\title{
"¿Dónde están los machos?" \\ Sindicalización anarquista, masculina y femenina, en la industria del dulce (Buenos Aires, 1920-1929)
}

\section{Ludmila Scheinkman}

IIEGE-UBA/Conicet

ludsch@gmail.com

"Es tanta la inconsciencia y la falta de hombría que se nota entre nuestras filas...", se quejaba amargamente el militante ácrata Manuel Durán, al reconocer que en su gremio, la Sociedad Obreros en Dulce Unidos, faltaba "cohesión", "energia", "acción" y "firmeza" para exigir a los patrones condiciones de trabajo más humanas y una jornada laboral de ocho horas. Por eso no dudaba, el viril y comprometido anarquista, en blandir "el látigo de la crítica y repartir unos cuantos fustazos sobre las espaldas de los rémoras de hoy", que "más que hombres conscientes" parecian "muertos que caminan". ${ }^{1}$

El activista sindical, en una peculiar elección de palabras, no dudaba en asociar la consciencia y el compromiso militante en el gremio con cualidades de hombria y virilidad propias del universo masculino. Y a la inversa, la falta de fuerzas, de compromiso y de consciencia de clase, con la pasividad y la falta de hombria, caracteres estos que se asocian a ese "otro" de la masculinidad, es decir, al universo femenino.

Sin embargo, estas afirmaciones -que se repitieron asiduamente en el periódico- se tornan más significativas si atendemos a algunas de las características de los oficios nucleados por la organización en cuestión. Las industrias comprendidas en la producción de dulces (fábricas de galletitas, chocolates, bombones, dulces y afines), incluidas en la rama alimenticia que ya tenía una alta participación femenina (Lobato, 2007: 37-57), se feminizaron fuertemente en la coyuntura critica de fines de la década del 10 y tempranos años 20 , al ritmo de la mecanización, llegando incluso, en la década del 30 , a constituir la mayoría de la fuerza de trabajo. Del 7,3\% de los trabajadores en 1904, al 9,6\% en 1909, elevándose al 21,6\% en 1914, entre esa fecha y 1935 las mujeres

1. Manuel Durán, “De actualidad”, El Obrero en Dulce (EOD), n5, septiembre de 1920.

(Archivos, año IV, $\mathrm{n}^{\circ} 7$, septiembre de 2015, pp. 15-35) 
llegaron a constituir el 50,3\% de la fuerza de trabajo en estas fábricas (Scheinkman, 2013).

A la luz de estos datos cobra toda su relevancia que las referencias y los llamados a la unidad y la organización realizados por los militantes más comprometidos del gremio se construyeran casi sin solución de continuidad en un registro excluyentemente masculino. Este trabajo se propone dar cuenta de algunas de las tensiones en la construcción de las identidades militantes en clave de géneros, en el marco de una experiencia de sindicalización particular: la de las obreras y obreros del dulce durante la década del 20 en la ciudad de Buenos Aires, a partir del análisis de El Obrero en Dulce, el periódico de la organización gremial, inscrita dentro de la corriente del anarquismo. ${ }^{2}$

El período abordado por este artículo comienza luego del momento de máximo auge del gremio del dulce, en que numerosos conflictos huelguísticos estallaron en todas las casas del rubro (1918-1920). En febrero de 1919, como parte de este proceso, el Sindicato de Obreros en Dulce de tendencia ácrata, que se reorganizó y creció enormemente durante las grandes huelgas, se incorporó a la sociedad Unión Confiteros (UC) como una sección de la misma, aunque con organización y finanzas propias. En este periodo de conflictividad el gremio alcanzó su máxima expansión, llegando a contar en noviembre de 1919 con 1.086 cotizantes. De éstos, 973 pertenecian al sindicato del dulce, y $436(44 \%)$ eran mujeres (agrupadas junto a un pequeño porcentaje de menores que no es posible discriminar). A comienzos de 1920 ambos sindicatos se fusionaron, y en asamblea el 16 de abril de 1920 adoptaron la denominación "Sociedad Obreros en Dulce Unidos", lanzando el nuevo periódico, donde se manifestó la hegemonía ácrata, conquistada al calor de las grandes luchas del periodo anterior.

Entre 1920, en que los anarquistas asumieron la conducción, y 1929, último ejemplar disponible del periódico, el gremio experimentó un proceso de profundo retroceso plasmado en la salida irregular del periódico y en el descenso en la cantidad de socios. Este retroceso general en la afiliación fue mucho más agudo entre su componente femenino. Las mujeres, que se acercaron al gremio en el momento álgido de las huelgas, lo habian abandonado masivamente hacia 1922, cuando de las 436 (44\%) iniciales, solo quedaban unas 90 (15\%). En enero de 1926

2. Se han conservado 18 ejemplares del periódico, editado en Buenos Aires, gracias al celo coleccionista de Max Nettlau. Agradezco el acceso a este material, parte de la colección Latin American Anarchist and Labour Periodicals (1880-1940), del International Institute of Social History (IISH), Amsterdam, a Lady Giselle Heidenreich y al Arquivo Edgard Leuenroth (Unicamp). Hay disponible una copia en el Cedinci. 
(última fecha de la que disponemos balances detallados), sólo cotizaban 106 varones adultos. ${ }^{3}$

Son varios los factores que contribuyen a explicar el retroceso general del gremio ácrata en este periodo. Al contexto de reflujo en el movimiento obrero debemos sumar la situación particular del anarquismo, atravesado por profundos debates internos que impactaron en la política gremial, y particularmente a las decisiones en este terreno adoptadas por la FORA V, con la que se alinearon los anarquistas del dulce. Sin embargo, en este artículo nos concentraremos en uno de los aspectos de este retroceso, el de la abrumadora pérdida del componente femenino del gremio. Si bien las mujeres tuvieron gran participación en los movimientos huelguísticos y se sumaron al sindicato en momentos de conflictividad, cuando ésta decayó lo abandonaron. En ese sentido creemos que este éxodo femenino excede con mucho, por su agudeza, a la situación general de reflujo, y como tal obedece a causas específicas de la dinámica gremial interna. Por ello nos concentraremos en el análisis de su particular construcción identitaria, que redundó en una política reactiva hacia las mujeres.

Numerosos trabajos han explorado los posicionamientos ideológicos y doctrinarios del anarquismo sobre la "cuestión sexual" y femenina (Barrancos, 1990; Bellucci, 1990; Fernández Cordero, 2012; Ledesma Prietto, 2012). Estos han señalado las ambivalencias, tensiones y contradicciones en el discurso libertario sobre la mujer, la familia y la sexualidad: disruptivo al poner en discusión la sexualidad, la subsumió sin embargo a lo "natural", a patrones de "normalidad", patologización, condenando lo carnal y otorgando a la mujer un papel sexual pasivo. Del mismo modo, su "contrafeminismo" se construyó desde una óptica masculina y paternalista, que apelaba a las mujeres en tanto "mediadoras" o "acompañantes". ${ }^{4} \mathrm{El}$ aliento a la participación femenina en la lucha social (virtualmente ausente en $E O D$ ), se hizo negando la especificidad de la opresión femenina (Barrancos, 1990: 232-294). Los trabajos sobre las iniciativas políticas y periodísticas de las mujeres ácratas también han señalado que si ellas encontraron en el anarquismo el espacio para una voz propia, se toparon con resistencias y hubo ciertamente posiciones

3. Hemos reconstruido estos datos a partir de la información -siempre incompletade las cotizaciones, aparecida en UC (enero de 1920) y EOD (todos los ejemplares disponibles). La carta orgánica del sindicato de obreros en dulce establecía una cuota mensual de $\$ 1$ para los varones adultos, y de $\$ 0,50$ para las mujeres y los menores de 16 años. "Reglamento - Carta orgánica del Sindicato de obreros en dulce afiliado al sindicato", UC, febrero de 1919 .

4. Si bien adherian a la idea de una utopia igualitaria, mantenian concepciones conservadoras de las mujeres en términos de minoridad, atraso y cuasi esclavitud, resaltando su rol "natural" como madres. 
contrarias y hostiles (Barrancos, 1996b; Ansolabehere, 2000; Lobato, 2000; Vasallo, 2007; Fernández Cordero, 2012; Norando y Scheinkman, 2012). Esto llevó a Dora Barrancos a afirmar que, hasta fines de la década del 20, "el feminismo anarquista parece localizarse "atrás" de la marcha emprendida por burgueses y reformistas" (1990: 294). Nuestro trabajo dialoga con esta bibliografia y se vincula también con el incipiente campo de trabajos sobre las masculinidades de los trabajadores (Archetti, 1998; Palermo, 2007; Gutiérrez, 2013; Klubock, 1992, 1998), y de modo general con aquellos autores que han atendido al papel de las mujeres en las organizaciones políticas de izquierda (Lobato, 2007; Nari, 2004; Valobra, 2015; entre otras).

Nos proponemos mostrar aquí que la identidad del obrero en dulce se construyó sobre bases masculinas, pero no vinculadas a la figura del varón proveedor, sino ligadas a la hombría, la virilidad, el "ser machos" y "hombres de verdad", construyendo para ello en oposición la figura de los "impotentes", los "eunucos" y los muertos que caminan. Una construcción que enraizaba en y reforzaba la norma heterosexual imperante, donde la masculinidad operó como lenguaje de la dominación, y la otredad de lo femenino funcionó como fantasma, invisibilizado. Nos interesa reconstruir las tensiones y conflictos entre la ideología libertaria masculina y la experiencia concreta de construcción gremial en espacios laborales en los que la presencia femenina se estaba tornando determinante; y los límites que dicha apelación, reactiva hacia las mujeres, planteó para la viabilidad del proyecto sindical en un contexto de profunda crisis del anarquismo forista (Anapios, 2011).

En primer lugar, trazaremos un breve recorrido por el desarrollo del gremio y los problemas que enfrentó, para luego introducirnos en la problemática construcción de la identidad gremial masculina. Por último, ahondaremos en el lugar de las mujeres, tanto en el periódico como en la construcción sindical. Basaremos nuestro trabajo en el análisis de $E O D$, el vocero con el que desde 1920 los militantes del sindicato se expresaron, comunicaron y emprendieron la labor gremial. El análisis de este documento nos permite indagar profundamente en los avatares de la construcción sindical que no encontraron un lugar en diarios como La Protesta o La Vanguardia.

\section{La Sociedad Obreros en Dulce Unidos y los problemas de la unificación gremial}

No fue una tarea sencilla para los militantes ácratas consolidar el sindicato del dulce. La Sociedad Obreros en Dulce Unidos se conformó en 1920 a partir de la unificación de las dos sociedades que nucleaban a los trabajadores del dulce: la sociedad de Confiteros, socialista y afiliada a 
la FORA IX, y la Sociedad de Obreros en Dulce, de tendencia anarquista. Durante más de una década los militantes socialistas habian tratado de impulsar una unificación de los productores de dulces a partir del sindicato de confiteros, tratando de incluir también a los trabajadores fabriles. Pero la unificación recién logró fraguar al calor de las grandes huelgas que experimentaron las fábricas del rubro entre 1918 y 1920.

El sindicato se componía tanto de trabajadores de confiterías como de fábricas. A partir de las grandes huelgas de 1918 y 1919, se pobló de obreras fabriles, quienes tuvieron una importante participación en los conflictos. Estas llegaron a constituir, en el momento álgido de las huelgas (octubre y noviembre de 1919), el 44\% de los afiliados del sindicato del dulce, junto a un pequeño porcentaje de menores que no es posible discriminar. Como vimos, el componente femenino del gremio decreció a un $15 \%$ en 1922, para desaparecer en 1926. Dicho año se mencionaba que la delegada y las "compañeritas" de la fábrica La Perfección habian rechazado en asamblea seguir cotizando al sindicato, y en 1929 el periódico aún lo lamentaba. ${ }^{5}$ El componente femenino del gremio aumentó en los momentos de conflictos, pero decreció en los momentos de calma, y no encontró un espacio institucional para expresarse ni en la conducción del mismo, ni en el periódico.

El primer número de la publicación del gremio, EOD, apareció el 1 de mayo de 1920 y levantaba las banderas del comunismo anárquico. Sin embargo, hasta 1922 el gremio no se afilió a ninguna federación obrera, una clara concesión de la militancia ácrata en favor de la unidad con sindicalistas y socialistas. La salida del periódico se propuso mensual, periodicidad que respetó en sus tres primeros años. En 1922 se incorporó a la FORA del V Congreso, y a partir de 1923 sufrió importantes modificaciones, profundizándose un lento declive en las afiliaciones, particularmente visible en el retroceso de la composición femenina en el gremio. Los congresos anarquistas de 1923 de la Federación Obrera Local Bonaerense y la Federación Obrera Provincial de Buenos Aires, en los que se combatió acerbamente la llamada "organización por industria", y el IX Congreso de la FORA V, que rechazó la posibilidad constituir federaciones regionales de oficios, impactaron de forma negativa en la organización. A partir de 1924 la publicación se hizo efimera e irregular, con uno, dos o tres ejemplares al año, evidencia de la difícil situación organizacional y financiera que atravesó. Los últimos números, casi ilegibles, son de 1929; si bien el gremio continuó su dificultosa existencia, atravesó una profunda crisis, y desconocemos las derivas de la publicación.

5. "Nuestra vida gremial. En la fábrica La Progresista", EOD, marzo de 1926; "Nuestro movimiento en la capital. La Progresista", EOD, noviembre de 1929. 
Como dijimos, la unificación de las sociedades en 1920 se había dado de forma tardía, luego de las grandes huelgas de 1918-1920. Con la excepción de este extraordinario momento de actividad y participación, en el que la presencia femenina en los conflictos fue central, no se trató de un gremio destacado por su magnitud, nivel de organización o actividad huelguística. Un sentimiento de "inferioridad" por "el estado desastroso del gremio" puede advertirse como un rasgo distintivo a lo largo de la prensa. Así se señalaba en sus páginas: "Los obreros en dulce, como revolucionarios, no somos, digamos, un gremio en el que valga la pena fijar la atención. Sus luchas no trascienden de su propio círculo. Y si alguna ha trascendido, no habrá sido más que para demostrar un pequeño entusiasmo". ${ }^{7}$

En efecto, para propios y ajenos, no se trataba de una experiencia de sindicalización particularmente exitosa. Esta situación era la que se habian propuesto revertir los militantes del gremio por medio de la unificación. El trabajo de construir la organización sindical implicaba lograr aunar a los trabajadores en base a aquellos criterios que los unificaban en términos de intereses comunes como trabajadores del dulce y productores, frente a los "otros", los patrones, "viles explotadores" que vivian de su trabajo. ${ }^{8}$ Por lo tanto las referencias y los llamados a la unidad fueron centrales en el periódico.

Entre los múltiples clivajes que dividieron a los trabajadores, las diferencias de cualificación y jerarquía fueron las más claramente percibidas y cuestionadas. Sin embargo, no fueron las únicas. La construcción de la identidad militante de estos obreros fue racializada, y la figura del militante consciente inmigrante o descendiente de inmigrantes blanco, se contrapuso a la de los "nativos" pasivos y oprimidos, caracterizados como "pobre gente", a la que "desde niños ya les enseñan a ser esclavos". ${ }^{9}$

Sin embargo, de entre los factores que atentaban contra la unidad, aquellos referidos a diferencias de oficio, "arte" y calificación fueron percibidos agudamente ya que el gremio reunía tanto a trabajadores artesanales de confiterías como a operarios de fábricas. Sobre todo en algunas grandes y afamadas confiterías como Las Violetas, El Molino o La Perla del Once, entraban en juego fuertemente las calificaciones de los "confiteros finos", por debajo de los cuales existía toda una gama de trabajadores menos cualificados. La tensión entre estos y con los

6. EBRO, "Nuestro estado actual", EOD, agosto de 1920.

7. "Nosotros. En Buenos Aires", EOD, junio de 1922.

8. Las apelaciones a la unidad y la organización, así como la contraposición con los patrones fueron rasgos comunes en la prensa gremial de la época (Lobato, 2009: 111-117, 157-164).

9. "De tierra adentro. Un día libre", EOD, julio de 1921. 
obreros fabriles fue permanente. Como señalaban en la redacción del periódico, "el elemento más refractario a la marcha hacia el porvenir, es el de las confiterias", ${ }^{10}$ y en ellas, los "confiteros "finos": los "maestros" percibían mejores salarios y se sentían más cercanos a las patronales. Según denunciaba el periódico, "los capataces y oficiales de las tres o cuatro confiterias que representan la flor y la nata de la industria" eran "krumiros" y carneros. ${ }^{11}$

Las diferencias jerárquicas en los talleres o fábricas también tenían un papel. Por ejemplo, en la Productora Americana se denunciaba el "oportunismo" de capataces y oficiales, que habian firmado un acuerdo con el patrón tras un conflicto, traicionando a los obreros rasos.

Compañeros, qué gran bajeza habéis cometido en firmar ese indigno papelucho, habéis querido distinguiros en la clase obrera, privilegiándoos una fracción, y olvidando a los demás, que tienen los mismos derechos que vosotros, en la vida, no solamente los técnicos tienen estómagos que alimentar y hogares que mantener, también los peones, aprendices, ayudantes y medios oficiales. ${ }^{12}$

Algunos trabajadores proponian acercamientos o intentos de "ganar" a los capataces y confiteros finos al gremio. ${ }^{13}$ Pero el conflicto fue permanente.

Frente a la situación de debilidad del gremio y a las múltiples divisiones que lo aquejaron, los trabajadores organizados realizaron intensas apelaciones a la unidad. La unificación del sindicato fue un intento por superar las divisiones politicas que fraccionaron a los trabajadores del dulce. Pero también trataban de superar las diferencias de cualificación y jerarquía, y "todas estas divisiones de compañeros, que debido a su negligencia son los más explotados", demostrando "con hechos prácticos, las ventajas que les puede reportar estar unidos". ${ }^{14}$ Ahora bien, los llamados a la unidad se cimentaron sobre una construcción identitaria singular, anclada en la masculinidad, que pasaremos a explorar a continuación.

10. "Del ambiente nuestro. Confiteros finos", EOD, julio de 1922.

11. "Notas breves. Nuestros héroes", EOD, agosto de 1921.

12. "Productora Americana. Oportunismo", EOD, julio de 1921.

13. Ver por ejemplo la nota de Gregorio Alvarez, "Mi modo de ver o pensar", EOD, octubre de 1920.

14. Isidoro Ayala, "Nuestro deber", EOD, agosto de 1920. 


\section{Nosotros y los otros: machos viriles y eunucos castrados}

La clave sobre la que se apoyaron los llamados a los trabajadores a unificarse, sumarse y construir el gremio fue la construcción de una identidad eminentemente masculina y atravesada por una fuerte connotación sexual. No fue peculiar de este gremio que el ámbito sindical se constituyera como un espacio de varones, asociado a ciertos valores de "masculinidad" (Lobato, 2000; Palermo, 2007; Klubock, 1992, 1998). Pero los valores en juego y, sobre todo, el virulento componente "viril" y sexual que incorporaron los obreros del dulce fueron características distintivas del mismo.

El grueso de las notas del periódico fueron escritas por varones, y se dirigian hacia otros varones, quienes eran a su vez los destinatarios mayoritarios del mismo. Mirta Zaida Lobato ha señalado la importancia del nombre en los periódicos obreros para construir una identificación y afianzar la identidad del grupo (Lobato, 2009: 68-71), y el propio nombre del periódico recalcaba que le hablaban a EL Obrero EN Dulce: singular, masculino, varón. Fue sumamente frecuente en la época que las prensas gremiales se titularan en términos masculinos referidos a la profesión (Lobato, 2009: 209-243). Siendo la producción de alimentos una tarea atribuida a las mujeres por la división sexual del trabajo imperante (Nari, 2004; Lobato, 2007), y más aun tratándose de la producción de dulces, confites y chocolates, dirigidos fundamentalmente a mujeres y niños, estas industrias estaban fuertemente feminizadas (Scheinkman, 2013), pero ya desde el mismo nombre el periódico se construyó en oposición a dicha feminización.

No sólo las colaboraciones femeninas escaseaban, sino que a menudo se ponía en evidencia que cuando hablaban a "los obreros", cuando los instaban a "ser hombres", no estaban empleando un plural universal e inclusivo, ni "hombre" era sinónimo de "humanidad" toda. Por el contrario, ser obrero y ser hombre equivalía a ser varón. Esto puede apreciarse claramente en distintas expresiones que pueblan sus páginas, como la que transcribimos: "El obrero que habiendo despertado del letargo [...] ve la miseria que impera en el hogar, ve a su prole desnuda y raquítica, a su compañera decaída y anémica, él, cansado y reumático [...] pide un poco más de pan para su familia, y un poco de libertad para él". ${ }^{15}$ Claramente, le hablaban a los varones. En este caso, al varón proveedor y padre de familia, que con su salario debía sostener a su mujer y a sus hijos, por los cuales luchaba y se organizaba.

Sin embargo, a diferencia de lo ocurrido con otros colectivos profesionales como los ferroviarios (Palermo, 2007), el rol proveedor no fue

15. Albino Diez, “¿Para qué estamos organizados?”, EOD, septiembre de 1920. 
un eje unívoco ni central de construcción de la masculinidad en este gremio. Las masculinidades, múltiples y en pugna, fueron producidas y negociadas desde las páginas del periódico (Archetti, 1998: 292). Donde más notorias se hicieron las disidencias entre los distintos colaboradores fue en la representación del varón en la familia. Mientras que algunos argumentaban en torno a la figura del varón que trabajaba y luchaba por su compañera e hijos, otros señalaban por el contrario que era por culpa del matrimonio que los obreros tomaban los puestos mejor remunerados de capataces, dejaban la lucha y traicionaban al gremio;

Porque formó el hombre un matrimonio tan descompaginado, que tiene que dar gusto a su nueva señora, la cual es tan caprichosa, tan poco humanitaria y tan celosa que no lo deja un momento tranquilo; y este es el motivo que el compañero recién casado $[\ldots]$ se abandone de la sociedad. ${ }^{16}$

En un artículo el militante José Martinez García era más extremo aún en su denuncia al matrimonio, y a los compañeros que se valian de sus mujeres e hijos como excusas para evitar la lucha que podia poner en riesgo sus trabajos. "He observado que son muchos", decía, "los que echan la pesada carga de sus culpas por traición, o abstención de la lucha, sobre los inocentes niños a quienes tanto dicen amar [...]. El resguardo entre faldas y pañales, es un argumento cómodo, pero que no me convence". En lugar de emplear la defensa del hogar obrero y la figura del "varón proveedor" como argumento para la lucha por mejores condiciones de trabajo, este escritor destrozaba esa figura, y llamaba a los trabajadores a permanecer solteros, y a las mujeres, a la huelga de vientres. ${ }^{17}$

El hecho de que gran cantidad de los trabajadores de estas industrias fueran mujeres, debilitaba el potencial unificador de la figura del varón proveedor y padre de familia. El trabajo femenino desnudaba que los varones no eran los proveedores únicos de los hogares proletarios. La figura del varón proveedor no fue central, y las claves de la masculinidad se construyeron sobre otros valores vinculados a las masculinidades vigentes en la época, y a ideologías del anarquismo local. La "hombria", la "energía", la "fuerza", la "potencia" y la "virilidad", eran alternativamente características que debía adoptar el sindicato, y caracteres asociados a los obreros conscientes que lo construian. La consciencia, valor recuperado por el anarquismo (Barrancos, 1996a,

16. Gregorio Álvarez, "Mi modo de ver o pensar", EOD, 10/1920.

17. José Martínez García, "El apego a la miseria. Los casados", EOD, junio de 1922. Esto se vincula con los llamados anarquistas a la participación femenina, que buscaban evitar que ellas desviaran a los varones de la acción y la militancia. 
1990; Suriano, 2001; Lobato, 2009: 45-52), se hallaba aquí vinculada a características masculinas. Para construir un gremio "fuerte y potente", "tenemos los obreros el deber de ir con tesón y energía, capacitándonos inteligentemente para la lucha de clases. Los [...] más capacitados o conscientes"18 debian "ilustrar" y ganar a la lucha a sus compañeros. Para "ser hombres", era necesario formarse e ilustrarse, "forjarse al calor de las ideas". Así, la hombría se asociaba a la fuerza pero también a la ilustración, la razón y la consciencia, que caracterizaban a la "minoría de obreros conscientes" de los sindicatos. ${ }^{19}$

El rol educativo y pedagógico fue fundamental para el gremio, preocupado por instruir, iluminar y despertar a los trabajadores: un obrero consciente era aquel que iba a construir una organización viril y fuerte. No escaseaban en el periódico citas de William Shakespeare, Émile Zola u Oscar Wilde y referencias a clásicos de la literatura europea como el Quijote, divulgaciones científicas y referencias a figuras como Galileo Galilei, Giordano Bruno o Jan Hus. No faltaban tampoco homenajes a Francisco Ferrer y la Escuela Moderna. Se publicaban artículos teóricos y doctrinarios, poemas de Ghiraldo y en la sede del local social funcionaba una biblioteca. A su vez, realizaban conferencias y puestas en escena de obras teatrales como Los muertos (1905) de Florencio Sánchez. ${ }^{20}$

Esta obra teatral fue de gran importancia: fue empleada para adoctrinar en el sentido de la masculinidad hegemónica, para ayudar a que los obreros se hicieran fuertes frente a los embates de la patronal. Es de relevancia tanto para el análisis que desarrollamos aquí, como para los mismos redactores y colaboradores del periódico, que la citaron profusamente. Lisandro, el personaje principal del montaje de Florencio Sánchez, era un "hombre sin carácter", es decir, un "muerto que camina", muerto en vida. Padre de familia entregado a la bebida y el vicio, había perdido su empleo, a su mujer (que lo abandonó por otro hombre), y a sus hijos. Es decir, era el fracaso de la masculinidad y la negación del varón proveedor, entregado a vicios y sin consciencia. Y es precisamente contra la figura arquetípica de los "muertos que caminan" que se construyó el ideal viril del obrero consciente. Los "pobres hombres", muertos en vida, "bueyes corneta entre la majada", eran los obreros sin consciencia, los carneros, los que sentian más afinidad por sus patrones que por sus hermanos proletarios, o simplemente los pasivos e indiferentes. En ese

18. Isidoro Ayala, "Nuestro deber", EOD, agosto de 1920.

19. Albino Diez, “¿Para qué estamos organizados?”, EOD, septiembre de 1920.

20. "Gran función y conferencia", $E O D$, octubre de 1920. Suriano ha denominado "intelectuales heterodoxos" a aquellos que, como Florencio Sánchez o Alberto Ghiraldo, comulgaban con el anarquismo pero eran más abiertos en sus posiciones respecto de la doctrina (2001: 76). 
sentido, se retomaba la prédica anarquista constituida sobre la base de oposiciones binarias (moral/inmoral, ignorante/ilustrado, consciente/ inconsciente) en las que se apelaba a la resistencia del individuo como sujeto transformador (Barrancos, 1990: 267; 1996b).

Pero en este caso, la construcción de estos "otros" fue mucho más allá. Se realizó en términos que se asociaban directamente a la homosexualidad, la debilidad y la pasividad. ${ }^{21}$ Aquellos contrarios al sindicato no sólo eran "muertos que caminan; [eran] eunucos sin comprensión". ${ }^{22}$ Es decir, eran hombres castrados, que no poseían miembro viril, "seres desgraciados y de tan baja moral, que renegando a su hombria, se arrastran cual reptiles [...] hombres sin un átomo de virilidad de machos". ${ }^{23}$ Esta falta de hombría se expresaba no sólo en la metáfora de la castración, sino también en referencias a la homosexualidad y la sumisión, como la que se empleó para caracterizar a los confiteros finos, "los más distinguidos en el arte de lamer lo que media entre ambas ancas; [...] al servicio ruin de la sin hueso, les salen canas en la misma casa que entraron cuando aún no tenían barba, los confiteros finos... ifinos de cuernos!". ${ }^{24}$ Aquellos que traicionaban a sus compañeros y estaban al servicio de sus patrones eran caracterizados con metáforas vinculadas a la homosexualidad, y a prácticas específicas, como lamer el ano del patrón, que podian entenderse como símbolos de sumisión, de falta de hombría. Además eran "cornudos", traicioneros, pasivos y femeninos, como se quejaba Jacobo Carro, cuando señalaba que "aquí, por donde se dice que hay tantos machos, no se ha dignado a pasar. Se ve bien claro. Se nos sigue como siempre explotando, se nos ordeña como a vaca mansa". 25

Por contraposición a los ataques sistemáticos y virulentos a los "muertos que caminan" es que cobra toda su fuerza la construcción relacional de la hombría realizada por estos trabajadores. Una construcción en diálogo, casi en espejo. Puesto que precisamente, se preguntaba José Martínez García, "con esa pasividad y esa débil actitud, ¿podrá llegar a ser fuerte el gremio?”. ${ }^{26} \mathrm{Y}$ la respuesta era clara. Lo que se necesitaba era el "espíritu sano y varonil de los trabajadores" 27 para "vigorizarse" y "engrandecerse", puesto que "el verdadero rol de lucha se puede en-

21. Sobre el tema de la homosexualidad, véase Jorge Salessi, 1995; Acha y Ben, 2004-2005.

22. "Movimiento gremial", EOD, abril de 1922.

23. E. Domingo, "Los pobres hombres", EOD, septiembre de 1920.

24. "Del ambiente nuestro. Confiteros finos", EOD, julio de 1922.

25. Jacobo Carro, "El pueblo", EOD, septiembre de 1920.

26. José Martínez García, "No hay que esperar a los muertos”, EOD, octubre de 1920.

27. Juan Verdugo, “Sus secuaces”, EOD, junio de 1921. 
tablar sólo viril y potente, cuando en la sociedad de un gremio hay una unión fuerte". ${ }^{28}$

La virilidad y la potencia masculina como valores pueden analizarse también para otros contextos, como el mundo del fútbol estudiado por Eduardo Archetti, donde en los "discursos" del estadio se jugaban evaluaciones masculinas de la autonomía, la dependencia, el control, la dignidad, la autoestima y la fidelidad a los compromisos (Archetti, 1998: 301). Así, las referencias ya mencionadas a los eunucos, los "muertos que caminan" y los impotentes sexuales, "presuponen la pérdida de autonomía de los adversarios y su incapacidad para actuar como verdaderos hombres" (ídem: 303). La oposición entre el papel activo del militante consciente, y el pasivo de los "muertos en vida", implicaba una degradación del papel de "machos" de unos, frente a la afirmación de los otros. Como ha indicado este mismo autor, "la afirmación de la propia masculinidad depende de privar al otro de la suya. El conquistado, el débil, el que no es un "hombre de veras" hace -o se sospecha que hace- cosas que atentan contra la naturaleza" (idem: 305). En claves (hétero)sexuales similares a las de los hinchas de fútbol -no tanto por su contenido explícito sino por el implícito-, los militantes del gremio del dulce construyeron su identidad y un mundo dividido entre "hombres de veras" e impostores: homosexuales, castrados, pasivos, femeninos.

Ahora bien, el presupuesto en el que se basó Archetti en su estudio para analizar el mundo del fútbol era que se trataba de un "mundo estrictamente masculino". Sin embargo, esta premisa no es válida para los militantes del dulce. De ahí lo curioso, y el hecho que hay que explicar: ¿por qué se estructuró la identidad militante en términos de esta masculinidad homófoba, tratándose, el espacio de la fábrica, de un ambiente mixto casi en un 50\%? Dicho de otro modo: ¿por qué se conformaron claves para interpretar y jerarquizar el lugar individual y social propio y ajeno, en términos de oposición entre varones, mediadas por la héteronorma?

El reforzamiento de la norma heterosexual y la necesidad de remarcar la hombria partian de una masculinidad en crisis, amenazada por la presencia femenina, que se retroalimentó y exacerbó en el contexto de crisis del gremio. Fue una forma de responder ante la crisis de identidad provocada por la feminización de la industria a partir de las transformaciones en el proceso de trabajo y la composición de la fuerza laboral (Scheinkman, 2014). Una feminización amenazante, puesto que estas mujeres desafiaban los roles genéricos dominantes de la domesticidad para ingresar en un espacio masculino como el fabril, tensionando la idea de "debilidad" y "pasividad" asociada a lo femenino y posicionán-

28. R. Costa, "Carta abierta”, EOD, septiembre de 1920. 
dose como mujeres "libres". En un contexto de creciente aislamiento del gremio, de quietismo en las fábricas en general y de pérdida de militantes (sobre todo femeninas), los anarquistas del dulce respondieron intensificando su cruzada contra aquellos que no se movilizaban. Y lo hicieron asiéndose de los discursos vigentes y los prejuicios morales de su tiempo, multiplicando improperios, acusaciones de cobardia y feminización; lo cual a su vez retroalimentó el alejamiento de las mujeres del gremio. La presencia femenina provocó una "desestabilización" en los términos identitarios construidos en las décadas anteriores, en las que había primado una composición laboral mayoritaria de varones, adultos y menores. Por ello la figura del varón proveedor perdió potencia, recalcándose las imágenes de hombria, virilidad, el "ser machos" y "hombres de verdad". Una construcción que, en oposición a los "impotentes", los "eunucos" y los muertos que caminan, reforzaba la norma heterosexual imperante.

La masculinidad se construyó en términos de "poder". Y el poder implica la "sumisión" del otro; necesita un "otro" sobre el que ejercerse (Foucault, 2006). "La afirmación de la propia masculinidad depende de privar al otro de la suya" (Archetti, 1998: 311), y en esos términos, la relación entre los hombres puede interpretarse parcialmente en función del dominio, el control y el poder. La identidad masculina en el gremio del dulce se construyó en clave de dominación/subordinación, lo cual en última instancia atentaba contra el mismo ideal libertario de la anarquía. A su vez, las relaciones patrón-obrero amenazaban esa construcción de la masculinidad, ya que los obreros eran los "dominados", los "pasivos", los explotados. De ahí la necesidad de recalcar el papel activo y consciente de los militantes. Pero cuando las fábricas se poblaron de mujeres, esta necesidad se intensificó. La masculinidad se constituyó como un lenguaje de dominación, en un contexto en el que los obreros eran los dominados. Por esto mismo, fue una construcción inestable, contradictoria y en tensión, donde no hubo posturas univocas pero sí tendencias dominantes, que necesitaban reforzarse continuamente por medio de la repetición. En ese sentido, el periódico se constituyó como un dispositivo de producción de ideologías de género, que Teresa de Lauretis ha denominado "tecnologías de género" (1989). Lejos de articular una identidad inclusiva que incorporara a las mujeres al gremio, los varones organizados respondieron cerrándose, remarcando su masculinidad, e incluso cayendo en posiciones "misóginas" y expulsivas.

\section{Las "otras" de los "otros"}

Las construcciones arquetípicas del género que poblaron el periódico y estructuraron al "obrero consciente" por oposición a los "muertos vivos" 
se operaron sobre el trasfondo de un borramiento o invisibilización del lugar femenino en las fábricas y en el gremio. Como señalamos al comienzo de este recorrido, las mujeres, inicialmente pocas, fueron cobrando relevancia en el sector industrial en la década del 20. Más aún, fue en la coyuntura crítica de fines de la década de 1910 y los tempranos años 20 cuando estas industrias se feminizaron fuertemente. No era asi en las confiterias, que continuaron siendo ámbitos esencialmente masculinos. Pero su presencia se tornó un dato más que destacable en las fábricas, al punto que, hacia mediados de la década del 30, eran mayoria.

Es decir que en el período en que cobró mayor relevancia el empleo femenino en estas industrias, los obreros sindicalizados varones elaboraron una identidad anclada fuertemente en lo masculino y la virilidad sexual, a la vez que borraban el lugar de lo femenino en el gremio, mostrando incluso en ocasiones una misoginia considerable. Como hemos apuntado, la participación femenina en el periódico fue sumamente limitada. Sólo 5 notas fueron firmadas por mujeres en los 18 ejemplares del periódico conservados, de 4 páginas cada uno. Aun así, la presencia femenina saltaba a la vista en las notas gremiales, donde no podía ocultarse, puesto que las mujeres fueron parte considerable de la fuerza de trabajo y participaron activamente en las huelgas. En la sección gremial se mencionaba, por ejemplo, que en la casa Trampolsky se había iniciado una huelga por el despido y posterior encarcelamiento de una compañera. ${ }^{29}$ En la fábrica de dulces La Ciudad de Viena las compañeras habian hecho abandono del trabajo para lograr la reincorporación de la delegada despedida, ${ }^{30}$ y también era una delegada quien centralizaba las cotizaciones de las "compañeritas" de la fábrica La Progresista. ${ }^{31}$

De todos modos, aun cuando mencionaban a las mujeres, lo hacian en términos masculinos. Así por ejemplo, en otro conflicto en La Ciudad de Viena en septiembre de 1920 se recalcaba "la acción viril entablada" por "las infatigables compañeras [...] siempre latentes, dispuestas a la acción". ${ }^{32}$ Respecto del mismo conflicto se señalaba, un mes más tarde, que "el obrero en dulce en general parece que se va dando cuenta de lo que ha sido y lo que debe ser; ahí está el ejemplo de La Ciudad de Viena, los compañeros de ambos sexos, con altivez y hombria se hacen respetar". ${ }^{33} \mathrm{O}$ se reclamaba "que ni un solo obrero u obrera deje de gozar de estas mejoras! Todos como un solo hombre, luchemos en la

29. "Última hora", EOD, octubre de 1920.

30. "Movimiento gremial. En La Ciudad de Viena", EOD, agosto de 1920.

31. "Nuestro movimiento en la capital. La Progresista", EOD, noviembre de 1929.

32. "Movimiento gremial. En La Ciudad de Viena", EOD, septiembre de 1920.

33. Albino Diez, “¿Para qué estamos organizados? (Conclusión)”, EOD, octubre de 1920. 
organización". ${ }^{34}$ Es decir, cuando se las reconocía, se lo hacía subsumiéndolas a la identidad masculina dominante. Y cuando las mujeres tomaban participación en los conflictos, adquirian características de virilidad, fuerza y hombria propias de lo masculino.

Si bien las mujeres tuvieron un importante papel en las huelgas y conflictos, las relaciones entre varones y mujeres en las fábricas fueron tensas. En ocasiones primó la solidaridad, pero en otras el rechazo e incluso el abuso. En la fábrica La Royal, un compañero que abusaba de sus camaradas de trabajo había sido molido a golpes por dos compañeros varones en una asamblea. ${ }^{35}$ En La Limeña, los compañeros eran "unidos y fuertes" pero no agremiaban a las mujeres que trabajaban en la fábrica. El periódico lo señalaba como un error, sin embargo los llamados a la agremiación femenina estuvieron virtualmente ausentes. ${ }^{36}$ Una de las pocas notas escritas por mujeres había sido firmada por una trabajadora de la fábrica Introductora Americana, dirigida "a sus compañeras". Alli las llamaba a participar de las asambleas convocadas en la fábrica, dejando de lado sus miedos y prejuicios y haciendo frente a los varones que las insultaban y agredian:

Olvidad ese fanatismo que tenéis algunas compañeras de que en las asambleas vais a perder vuestro merecimiento; al contrario, en las asambleas es donde podemos aprender a defender nuestros intereses; en la asamblea es donde la mujer explotada puede cultivar su mente; es nuestra escuela, porque otra no tenemos. No importa, compañeras, que algunos compañeros indignos de serlo, que nos ultrajan en la fábrica con sobrenombres groseros, para que dejéis de concurrir a las asambleas: venid y os convenceréis de que en ellas la mayoría de los compañeros observan la mayor fraternidad y respeto para con nosotras. ${ }^{37}$

Este relato muestra el grado de exclusión, maltrato y tensión que podía llegar a vivirse en algunos espacios fabriles, a un punto tal que algunas compañeras temían perder su "merecimiento" en las asambleas del sindicato. Además eran objeto de insultos, maltratos y ultrajes por sus compañeros. Esto se criticó desde las páginas del periódico, pero poco se hizo por modificar esta situación. Las apelaciones a las mujeres a organizarse, llamativamente escasas, no fueron parte de la agenda del

34. S. Ferro, "El despertar del gremio", EOD, octubre de 1920.

35. "Movimiento gremial. La Royal”, EOD, julio de 1921.

36. "Movimiento gremial. La Limeña", EOD, agosto de 1921.

37. M.E.A., “A las compañeras de la Introductora Americana”, EOD, 1 de mayo de 1920. 
gremio, contrastando con otros periódicos de gremios con gran participación femenina, como por ejemplo El Obrero Textil, en la década del 30 (Norando y Scheinkman, 2011).

Por otro lado, como en el campo libertario de la época, en este periódico hubo también artículos teóricos respecto de "la mujer", el amor libre, el matrimonio y la familia. De la decena de notas dedicadas a la reflexión teórica sobre estos temas, todas con excepción de una fueron escritas por varones. Varias de estas tuvieron un fuerte contenido misógino, como una de Jacobo Carro donde se señalaba sobre la mujer que, "puesto que en ella no existe ese espíritu de lucha a que los hombres se han dado, hay que tratarla como es. Esclava, ignorante y, por lo tanto, engreída". ${ }^{38} \mathrm{Si}$ bien las mujeres eran activas en las protestas y en la organización de base, dificilmente este tipo de apelaciones contribuyeran a favorecer su participación activa o dirigente en el sindicato o en el periódico. Sin embargo, la posición sobre las mujeres en el periódico fue polifónica (Fernández Cordero, 2013), y no hubo una posición homogénea sobre el tema. En el número siguiente, una nota tomaba una posición clásicamente tutelar sobre las mujeres, muy distinta de la anterior. Allí se llamaba a la "compañera", señalando: "La Anarquía no te desprecia porque hayas sido engañada, porque vayas a ser madre, porque hayas disfrutado del amor sin cadenas. Ven con nosotros, no con sumisión ni con vergüenza: con la frente erguida". ${ }^{39}$

La única nota doctrinaria escrita por una mujer señalaba que ellas no eran menos que los varones: "Subleva sólo pensar que la sociedad actual nos tenga como inferiores"; ${ }^{40}$ era la educación recibida la que castraba sus espíritus y su desarrollo intelectual. En el mismo ejemplar, otro artículo criticaba el aborto -el maternalismo extremo fue casi invariante en el anarquismo hasta los años 30-y destacaba el "instinto maternal" "natural" de las mujeres. Se trataba de un diálogo en el que un médico se negaba a practicarle un aborto a una jovencita embarazada, llena de vergüenza y angustia, que temía por su honra. El médico concluía triunfante que "se ha despertado en ella la maternidad, que duerme en todas las mujeres... Ya no teme la vergüenza, se siente orgullosa de ser madre [...]: "Bendita tú eres entre todas las mujeres"”, ${ }^{41}$ una llamativa referencia bíblica. A la par, notas más disruptivas llamaban a las mujeres a la "huelga de vientres" y a negarse a "seguir pariendo esclavos". ${ }^{42}$ Había condenas a la prostitución, en que se culpaba a los viles explotadores

38. Jacobo Carro, "La mujer", EOD, julio de 1921.

39. Isaac Jiménez, "A ti compañera”, EOD, agosto de 1921.

40. S.S., "Para la mujer", EOD, noviembre de 1924.

41. Santiago Gaston, "Maternidad (Diálogo)", EOD, noviembre de 1924.

42. José Martínez García, "El apego a la miseria. Los casados”, EOD, junio de 1922. 
que "seduciendo a obreritas" 43 habían arrojado a "nuestra hermana, compañera e hijas" a la prostitución, "última escoria humana"; 44 y otras que la justificaban señalando que "todo el mundo es a la vez prostíbulo y cárcel para los pobres". ${ }^{45}$

Como vemos, las posiciones teóricas sobre las mujeres fueron variadas. Sn embargo, los intentos por sumar a las mujeres al gremio fueron llamativamente escasos. No es casual que una de las pocas voces femeninas en el periódico dejara entrever una profunda discriminación en muchos espacios laborales: como vimos, las mujeres temían "perder su merecimiento" en las asambleas, y eran "ultrajadas" por algunos varones con "sobrenombres groseros", para que no concurrieran a las mismas. Este desinterés por la participación femenina contrasta con la política deliberada, y contrarrevolucionaria, de acción sobre las mujeres que llevó a cabo la Liga Patriótica Argentina, organización parapolicial de derechas que construyó "Escuelas para obreras" en casi todas las fábricas importantes de este rubro. ${ }^{46}$ Iniciativas que buscaron educar y adoctrinar a las mujeres para alejarlas del anarquismo y del sindicato. Junto a la política de agremiación por oficios, y al retroceso general del anarquismo en la década, atravesado por profundos conflictos internos, es posible pensar que una de las razones del declive del gremio del dulce, que perdió a su militancia femenina, fue esta misma identidad masculina, que resultó expulsiva para las mujeres. La ausencia de una política sistemática para incorporarlas al gremio y sumar sus reclamos, se retroalimentó así con el naufragio de la prédica anarquista.

\section{A modo de conclusión}

Como hemos visto en estas páginas, la identidad gremial en el sindicato del dulce se ancló sobre una interpretación particular de la masculinidad elaborada por los militantes anarquistas vinculada a la "hombria", la "virilidad" y la acción. Es decir, un lenguaje de "poder", frente a la sumisión, la subordinación y la pasividad de los "otros". En una rama industrial en la que las mujeres tenían un gran peso, la figura del varón proveedor no logró hacer pie. Sin embargo, en un contexto de retroceso general del gremio, lejos de conformar una identidad inclusiva que favoreciera la participación de las mujeres, los militantes

43. Isaac Jiménez, “A ti compañera”, EOD, agosto de 1921.

44. "El fantasma del verdugo", EOD, octubre de 1920.

45. José Martínez García, "Todo el mundo es a la vez prostíbulo y cárcel para los pobres", EOD, abril de 1922.

46. Por ejemplo, Liga Patriótica Argentina, Comisión de Señoritas, Memoria de diez escuelas obreras, 1924 - Mayo - 1925, Buenos Aires: Ventriglia. 
del dulce recrudecieron un discurso cimentado en la superioridad de los hombres viriles y conscientes, frente a los muertos vivos, pasivos y sometidos. Esta construcción que buscaba interpelar a los trabajadores que abandonaban la organización en un contexto de crisis política y organizativa del anarquismo forista llevaba implícita la oposición dominación/subordinación, que en última instancia atentaba contra el ideal libertario anárquico, y terminó por profundizar la agonía del gremio. Si la necesidad de recalcar el papel activo y consciente de los militantes se conformó en buena medida como interpelación a sus compañeros y como desafio a la relación patrón-obrero, en la que los trabajadores eran los "dominados", "pasivos" y explotados, cuando la presencia femenina "amenazó" la masculina en las fábricas, cuando la dirigencia sindical entró en crisis, la construcción masculina se intensificó. La masculinidad se alzó como lenguaje de la dominación, aún en un contexto en el que los obreros eran los dominados, y su construcción fue inestable, contradictoria.

En este marco de contradicciones, queremos destacar que la militancia anarquista en este periodo fue sumamente riesgosa y sacrificada. Perder el trabajo, pasar una temporada en prisión e incluso en algunos casos poner la vida en juego fueron riesgos que estos militantes asumieron. No obstante, creemos que el eje de articulación, que interpelaba a lo más "intimo" de los obreros (su sexualidad y hombria) para tratar de sumarlos al gremio, mostró sus límites. Al construirse en estos términos, los obreros cavaron la fosa del proyecto de unificación, puesto que dejaron fuera, de hecho, al 50\% de la fuerza de trabajo. Creemos que este factor debe ser ponderado a la hora de evaluar las dificultades organizacionales del gremio y el naufragio de la unificación, que no supo "ganar" a su causa a las mujeres, siendo, por el contrario, expulsivo para ellas.

\section{Bibliografia}

Abad de Santillán, Diego (2005), La FORA. Ideología y trayectoria del movimiento obrero revolucionario en la Argentina [1933], Buenos Aires: Libros de Anarres.

Acha, Omar y Pablo Ben (2004-2005), "Amorales, patoteros, chongos y pitucos. La homosexualidad masculina durante el primer peronismo (Buenos Aires, 1943-1955)", Trabajos y Comunicaciones, pp. 30-31.

Anapios, Luciana (2011), Debates y conflictos internos en el anarquismo argentino durante la entreguerras, Tesis de maestria en Historia, IDAES, Universidad Nacional de San Martín.

Ansolabehere, Pablo (2000), "La voz de la mujer anarquista", Mora, no 6, Buenos Aires, pp. 109-119. 
Archetti, Eduardo P. (1998), "Masculinidades múltiples. El mundo del tango y del fútbol en la Argentina", en Daniel Balderston y Donna Guy (comps.), Sexo y sexualidades en América Latina, Buenos Aires: Paidós, pp. 291-312.

Barrancos, Dora (1990), Anarquismo, educación y costumbres en la Argentina de principios de siglo, Buenos Aires: Contrapunto.

- (1996a), La escena iluminada: ciencias para trabajadores, 1890-1930, Buenos Aires: Plus Ultra.

- (1996b), "Mujeres de nuestra tribuna: el dificil oficio de la diferencia", Mora, $n^{\circ} 2$, Buenos Aires, pp. 125-143.

Bellucci, Mabel (1990) "Anarquismo, sexualidad y emancipación femenina: Argentina alrededor del 900”, Revista Nueva Sociedad, n 109, pp. 148157.

De Lauretis, Teresa (1989), "La tecnología del género", disponible en: http:/ / www.caladona.org/grups/uploads/2012/01/teconologias-del-generoteresa-de-lauretis.pdf. Tomado de Teresa De Lauretis, Technologies of Gender. Essays on Theory, Film and Fiction, Londres: Macmillan Press.

Fernández Cordero, Laura (2012), "The Anarchist Wager of Sexual Emancipation in Argentina, 1900-1930", en Geoffroy De Laforcade y Kirwin Shaffer (eds.), In Defiance of Boundaries: Anarchism in Latin American History.

- (2013), "Para leer el concierto de la prensa anarquista: Un ejercicio inspirado en Mijail Bajtín", Adversus, n 24, junio, pp. 68-91.

Foucault, Michel (2006), Vigilar y castigar [1975], Buenos Aires: Siglo XXI, Gutiérrez, Florencia (2013), "Desigualdad social, masculinidad y cualificación en el sindicalismo azucarero. Tucumán, 1944-1949”, Anuario IEHS, $\mathrm{n}^{\circ}$ 28, Tandil, pp. 59-75.

Klubock, Thomas (1992), "Sexualidad y proletarización en las minas de El Teniente", Proposiciones, $\mathrm{n}^{\circ} 21$, pp. 45-54.

- (1998), Contested Communities: Class, Gender and Politics in Chile's El Teniente Copper Mine, 1904-1951, Durham: Duke University Press.

Ledesma Prietto, Nadia (2012), "Apuntes sobre la eugenesia y la libertad sexual en el discurso de dos médicos anarquistas: Argentina, 1930-1940”, Nomadias, $\mathrm{n}^{\circ} 16$, pp. 75-97.

Lobato, Mirta Zaida (2000), "Lenguaje laboral y de género. Primera mitad del siglo XX", en Fernanda Gil Lozano, Valeria Silvina Pita y María Gabriela Ini (dirs.), Historia de las mujeres en la Argentina. Siglo XX, vol. 2, Buenos Aires: Taurus, pp. 95-116.

- (2007), Historia de las trabajadoras en la Argentina (1869-1960), Buenos Aires: Edhasa.

- (2009), La prensa obrera, Buenos Aires: Edhasa.

Nari, Marcela María Alejandra (2004), Politicas de maternidad y maternalismo politico: Buenos Aires, 1890-1940, Buenos Aires: Biblos.

Norando, Verónica y Ludmila Scheinkman (2011), "La Huelga de los Conventillos, Nueva Pompeya, 1936: Un aporte a los estudios sobre género y clase", A Contracorriente, vol. 9, n 1, otoño, pp. 1-37. 
- (2012), "«Hastiadas de tanto y tanto llanto y miseria..., de ser el juguete, el objeto de los placeres de los infames explotadores". Visibilizando a las mujeres proletarias", Historia Regional, año XXV, n 30, pp. 167-190.

Palermo, Silvana (2007), “¿Trabajo masculino, protesta femenina? La participación de la mujer en la gran huelga ferroviaria de 1917", en María Celia Bravo, Fernanda Gil Lozano y Valeria Pita (comps.), Historias de luchas, resistencias y representaciones: Mujeres en la Argentina, siglos XIX y XX, Editorial de la Universidad Nacional de Tucumán, pp. 91-121.

Salessi, Jorge (1995), Médicos, maleantes y maricas: higiene, criminología y homosexualidad en la construcción de la nación argentina (Buenos Aires, 1871-1914), Rosario: Beatriz Viterbo.

Scheinkman, Ludmila (2013), "Una infancia no tan dulce. Publicidades, consumo y trabajo infantil en las fábricas de dulces, galletitas y afines de la Buenos Aires de principios de siglo XX", Actas de las IV Jornadas Nacionales de Historia Social, La Falda, Centro de Estudios Históricos "Prof. Carlos S.A. Segreti".

- (2014), "Estrategias patronales de organización y gestión del trabajo y la producción en las fábricas de dulces, chocolates y galletitas de la Ciudad de Buenos Aires (1880-1930)", en Perspectivas sobre la industria: Documento de Trabajo 1, Buenos Aires: Facultad de Ciencias Económicas, UBA.

Suriano, Juan (2001), Anarquistas: Cultura y politica libertaria en Buenos Aires, 1890-1910, Buenos Aires: Manantial.

Valobra, Adriana M. (2015), "Formación de cuadros y frentes populares: las mujeres en el Partido Comunista de Argentina, 1935-1951", Izquierdas, $\mathrm{n}^{\circ} 23$, pp. 127-156.

Vasallo, Alejandra (2007), "Sin Dios y sin Jefe", en Maria Celia Bravo, Fernanda Gil Lozano y Valeria Pita (comps.), Historias de luchas, resistencias y representaciones: Mujeres en la Argentina, siglos XIX y XX, Editorial de la Universidad Nacional de Tucumán, pp. 63-90.

Titulo: "Where are the machos?" Anarchist unionization experiences of male and female workers in Buenos Aires's sweet industry (1920-1929)

Resumen: Este trabajo da cuenta de las tensiones en la construcción de identidades militantes en clave de géneros, en la experiencia de sindicalización de los obreros y obreras del dulce porteños durante la década del veinte, analizando El Obrero en Dulce, periódico de la organización gremial anarquista Sociedad Obreros en Dulce Unidos. En una rama industrial que se estaba feminizando, en un contexto de crisis del anarquismo, los activistas varones construyeron una identidad militante en clave excluyentemente masculina. Creemos que este factor debe ser ponderado a la hora de evaluar las dificultades organizacionales 
del gremio, que no supo "ganar" a su causa a las mujeres, siendo, por el contrario, expulsivo para ellas.

Palabras clave: sindicalización, identidades políticas, identidades de género, masculinidades

Abstract: This paper intends to unravel gender tensions in the construction of militant identities, in the context of the unionization experience of male and female workers in the sweet industries, during the 1920's. We focus on Buenos Aires, analyzing El Obrero en Dulce, the journal of the anarchist union Sociedad Obreros en Dulce Unidos. We seek to show that one of the reasons for the limited success of the trade organization was the expulsive masculine militant identity constructed by male militants, and their inability to win women workers in a branch of industry were the proportion of the female labor force was increasing rapidly.

Key words: unionization, political identities, gender identities, masculinities

Recepción: 4 de abril de 2015. Aprobación: 20 de junio de 2015. 